Int. J. Dev. Biol. 58: 643-647 (2014)

doi: $10.1387 / \mathrm{ijdb} .140245 \mathrm{sr}$

\title{
Two decades of reproductive biomedicine and stem cell biology in Iran: the Royan Institute
}

\author{
SOPHIE ROUSSEAUX* \\ INSERM, U823, Université Grenoble Alpes, Institut Albert Bonniot, Faculté de Médecine, \\ La Tronche Cedex, France
}

\begin{abstract}
The Royan Institute in Tehran, Iran, has developed over the last 23 years and is today a leading institute in the Middle East dedicated to research and technological development programs coupled with clinical activities in the area of reproductive and stem cell biology. Here an insight into its history and future plans is given through a dialogue with one of its pioneer members and current Director, Prof. Hamid Gourabi. The Royan Institute is a remarkable example of a successful achievement in organizing basic and translational research under challenging environmental conditions.
\end{abstract}

KEY WORDS: reproductive biomedicine, stem cell biology, regenerative medicine, assisted reproductive technologies

\section{Context}

The role of Persia in culture and science goes back deep into history with figures such as Avicenna, Razi and many other scholars who contributed to building the universal human cultural and scientific heritage. During my visit to Iran for the Royan Twin Congress, grouping the $15^{\text {th }}$ congress on Reproductive Medicine and the $10^{\text {th }}$ Congress on Stem Cell Biology and Development, organized by Royan Institute in Tehran, Iran, imaginary portraits of Avicenna and Razi gave me the feeling of the spirit that guides and reigns in this research institute.

The word "royan" means embryo in Persian. The Royan Institute, founded in 1991, has become a leading Iranian biomedical research center. As part of its policy to communicate with scientists in the world, the Royan Institute has kept regular contact with researchers in the field of reproductive biology, by sending information about their activity, as well as the program of their Annual Meeting. This is how I initially became acquainted with the Royan Institute.

Last September, I was invited there as an attendee and an award winner (http://www.royanaward.com/). I went to Iran, bearing in mind an account published in Nature by Rudolph Jaenisch of his experience in Royan in 2007 (entitled "An American scientist in Tehran"). This trip has been a great opportunity for me not only to visit this beautiful and culturally very rich country for the first time, but also to discover the Royan Institute for myself, appreciate the effort and meet the people supporting this growing and dynamic coupled research program and clinical activities in the areas of human reproductive medicine and stem cells.
Indeed, although some of my colleagues and friends had expressed concerns and even disapproval about my trip to Iran, the spontaneity, hospitality, enthusiasm, and above all, the curiosity of the people I met there, largely confirmed Jaenish's report. Although the country has a different language, environment and culture from my home country, and despite the little inconvenience that I had to wear a long jacket, long sleeves and cover my hair, I experienced one of the warmest welcoming I had ever encountered in my whole life. The other award winners and invited speakers, many of them also Westerners, seemed to have been equally well treated.

The program of the Twin Meeting (Fig. 1) included plenary sessions, with subjects of interest for both scientific communities, as well as parallel more topical sessions. Most sessions were in English since they involved Iranian as well as non-Iranian speakers, but two sessions were in Persian. The reproductive biology and medicine topics included: ovarian stimulation management, endometrium biology and uterine cavity assessment, sperm biology and various aspects of male infertility, reproductive genetics, cryobiology and fertility preservation, animal biotechnology, ethical issues, as well as psychological and educational issues raised by infertility treatments. Stem cell biology and technology sessions also covered fundamental aspects, as well as a large spectrum of medical applications, including the treatment of degenerative disease such as multiple sclerosis, osteoarthritis, glioblastoma and various cancers. Some of the invited speakers were already involved in active collaborative projects with teams of the Royan Institute. Some of the Iranian speakers, including some undergraduate scientists, presented their new results and achievements.

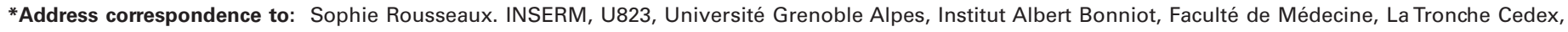
France. E-mail: sophie.rousseaux@ujf-grenoble.fr
}

Accepted: 13 November 2014

ISSN: Online 1696-3547, Print 0214-6282 
The whole meeting has been a unique experience. The general scientific level of the presentations was excellent and the questions, ideas and discussions following them were thought provoking and inspiring. Most of all, the contact with researchers and students at all levels has been extremely interesting and energizing. One of the main priorities of the Royan Institute is to help young scientists to meet other scientists and give opportunities for students. Indeed, for many Iranian young scientists and students, this meeting provides a unique situation where they can meet foreign scientists personally. In return, it gives invited speakers like me, a fantastic opportunity to meet many enthusiastic, spontaneous, intelligent, creative and highly motivated scientists, including senior, junior and future scientists.

We also visited the Royan Institute buildings in Tehran. I was impressed by the IVF clinical centre, which is conveniently localized right next to the buildings hosting the reproductive biology research labs and stem cell and development research labs. I was even more impressed when Prof. Hamid Gourabi, the President of the Institute, showed me the model of the future Royan Institute building in Tehran, which, he hopes, should be opening in three years.

The Royan is a highly dynamic institute, which by many ways, is at the cutting-edge of technological advances. It is dedicated to the improvement of human health and is also promoting high level of education for bright and highly motivated young women and men. However, like many activities in Iran, the Royan Institute also suffers greatly from the embargo imposed by the Western countries on Iran. Buying some reagents, such as antibodies or specific fluorescent probes, which are commonly used in any medical or research biology lab in the world, can be a major obstacle in Iran, which introduces great delays in research activities, and sometimes are even impossible to overcome. Of course, these obstacles and delays are detrimental to the progression of competitive science in Iran.

Despite all the obstacles resulting from the political and economic isolation of the country, the Royan Institute has obviously succeeded at creating and supporting highly dynamic research and technological development programs coupled with clinical activities. I was curious to know more about the secrets of this success and the people behind it, and I decided to ask Prof. Gourabi, one of the co-founders and the present President of the Royan Institute. I asked him about the original idea that sparked the project and motivated the Royan founders, the history and future developments of the Royan Institute, its impact on scientific life in Iran, and on the relationships between Iranian scientists and their colleagues in other countries.

\section{Dialogue with Prof. Hamid Gourabi}

\section{S.R. Would you please give us a brief history of the Royan Institute and its aims and objectives?}

H.G. The Royan Institute was established in 1991 by the late Prof. Saied Kazemi and his colleagues, as a non-governmental nonprofitable organization for Reproductive Biomedicine and infertility treatment. Considering the fast and remarkable achievements in the field of stem cell biology, the Royan Institute created, in 2002, a department dedicated to the study of embryonic stem cell lines, and later human induced pluripotent stem cells (iPSCs) and their differentiation into different types of cells including neural cells, cardiomyocytes and beta cells. In 2004, the other newly founded department of animal biotechnology joined the Royan Institute to optimize further the biological studies on reproductive medicine and stem cell biology. One of the resulting outputs of this strategy was the first successfully cloned sheep- named Royana- in the Middle East, in 2006.

\section{Today, what is your evaluation of Royan's achievements and its ability to reach the original aims?}

As pioneers in Assisted Reproductive Techniques (ART) in Iran, we now have the largest infertility treatment clinic in Iran and the Middle East region. Indeed, our infertility clinic is currently hosting over ten thousand infertile couples annually and at least 7000 ART cycles are managed each year with approximately $40 \%$ success rate. In addition, many other clinics have been established around the country with our educational and technical supports. The Royan Institute for Stem Cell Biology and Technology is providing a comprehensive and coordinated "bench to bedside" approach to regenerative medicine, as well as a greater understanding of the fundamental biology of stem cells, promoting a translational research to develop the therapeutic use of stem cells and novel cell-therapy approaches that can restore tissue functions in patients. The Royan Institute for Biotechnology, in addition to its successes in animal cloning and transgenic animal production, has recently made several important achievements, which include zona free somatic cell nuclear transfer (SCNT), the use of epigenetic modifiers to improve the outcome of SCNT, vitrified embryos, as well as novel approaches for the selection of intact sperm for Intra Cytoplasmic Sperm Injection (ICSI) based on sperm functional characteristics.

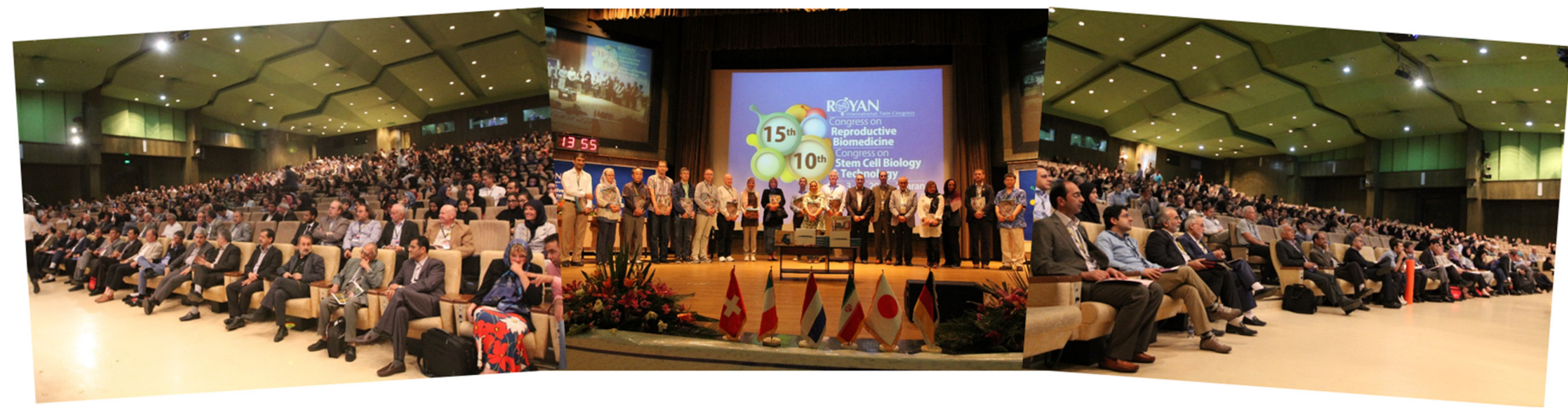

Fig. 1. Panoramic view of the Auditorium at the Razi Conference Centre during the Royan twin Meeting: 15th Congress on Reproductive Medicine and 10th Congress on Stem Cell Biology and Development, Tehran, Iran, September 2014. 


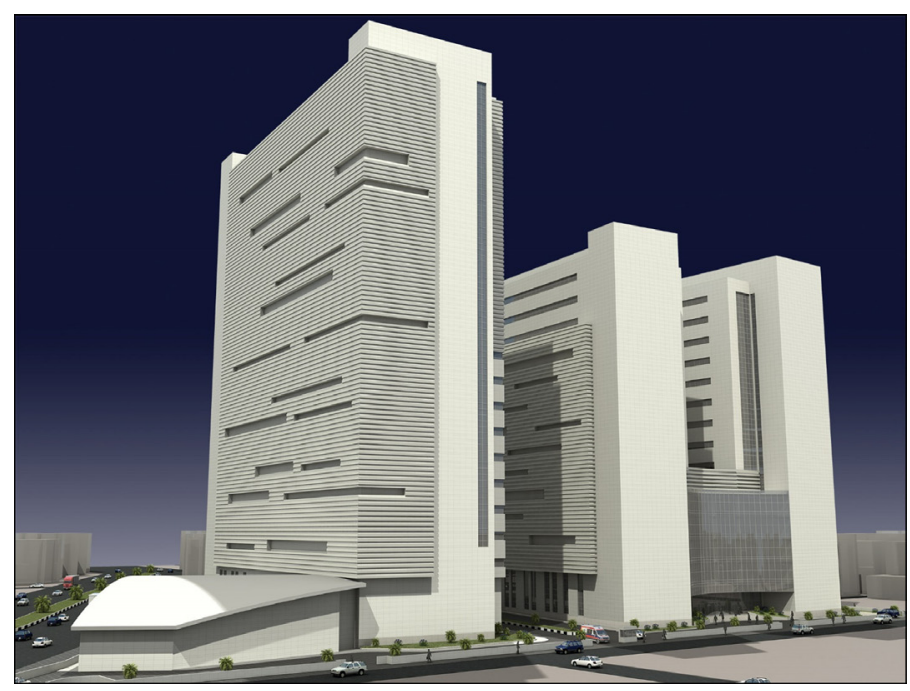

Fig. 2. 3D model of the future site of Royan Institute and its hospital.

These remarkable progresses should help the Royan Institute to meet its challenging objectives, which are to provide medical services to infertile individuals, as well as for patients suffering specific degenerative diseases or genetic disorders.

What are your plans for the future? When I visited the Royan Institute, you showed me a model of the future Royan Institute, which is about to be built in Tehran. Would you tell us more about this project? Why are you planning for a bigger building? Which activities are you planning to expand? How do you see the Royan Institute in the future?

The Royan Institute has recently made very important new findings in regenerative medicine. Presently several clinical trials in this field are being carried out and many new approaches are still being developed. The expansion of our biomedical research and new treatment protocols has inevitably prompted us to plan for a modern hospital, which would offer regenerative medicine services within the frame of clinically approved protocols and would allow us to extend clinical trials and research to reproductive biology and medicine. This hospital will consist of more than 75,000 square meters and an additional same space area will be dedicated to research and educational purposes (Fig. 2). We are also planning to build a cell manufacturing facility to provide products with the quality required for approved cell therapy protocols for all medical centres in Iran and countries in the region.

In its 2025 vision, the Royan Institute proposes to reach an international level of excellence in clinical research and technology and wishes to be a scientific reference in the areas of stem cell science and biotechnology, as well as in reproductive biomedicine and regenerative medicine.

What is the Royan Institute's policy in terms of training and its relationship with universities and other research institutes?

The Royan Institute's main objective is to educate and train young researchers in the required fields. A large part of the research projects carried out in the Royan Institute are performed by MSc or PhD students under the supervision of experienced advisors, in collaboration with different academic institutions in Iran and around the world. Additionally, international collaborations with other clinical research centres and universities in the world are aiming not only to build up strong scientific relationships but also to increase the reliability of the data and research findings.

You have been involved in the Royan Institute since the beginning. Would you tell us about your personal experience in Royan as a member and as its President?

At the time of the establishment of the Royan Institute, all of us were postgraduate students and there was no governmental budget. Good willing people helped us and we worked in very difficult conditions. I have experienced amazing moments in Royan. I am happy to see that today many patients solve their infertility problems here, and I wish to witness the cure of many diseases by cell therapy in our institute.

Hard work, the continual presence of pioneer researchers and physicians, a management stability for the past 23 years and support from the community are the main reasons for our success.

Were there any major obstacles and difficulties that you had to face and what were your general strategies to face the problems?

The major problems are due to budget restrictions caused by the sanctions imposed on our country. Indeed, the difficulties in getting access to laboratory equipment and materials represent a considerable obstacle for the Royan Institute's research activity. We hope that this situation will change in the near future.

Would you tell us about the evolution of ideas and the dynamics of the Royan Institute over the years? What are the key dates which were particularly important for the evolution of the Royan Institute?

During the first years after the Royan Institute was established, the situation was extremely difficult. We did not even have access to $\mathrm{CO}_{2}$ incubators and our colleagues had to adjust the percentage of $\mathrm{CO}_{2}$ by counting the bubbles of $\mathrm{CO}_{2}$ rising from a jar of water! In such conditions, obtaining reliable findings and preparing scientific papers were a double challenge for us. After several years of selfeducation and hard research work, the Royan Institute now annually

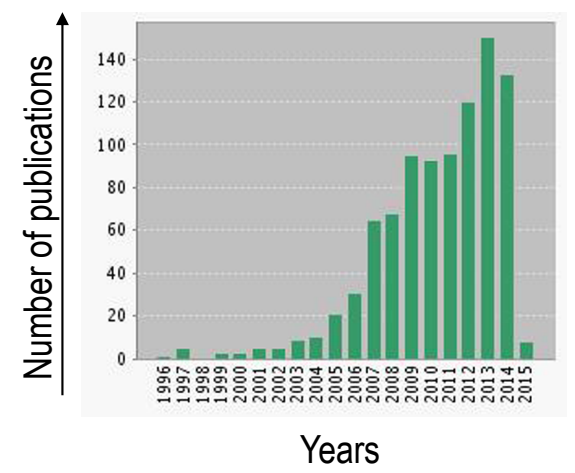

Fig. 3. Web of Knowledge citation report for the publications from the Royan Institute. Number of publications (left panel) and number of citations (right panel). 
publishes more than one hundred scientific papers in peer-reviewed journals (Fig. 3), and we hope that this will increase in the future. The increasing numbers of citations of the Royan published papers in the last few years reflects the improvement of the quality of the presented data. Now, our scientists at Royan Institute are proposing and testing new important scientific hypotheses, which hopefully will serve as a basis to develop new treatments for hard-to-cure degenerative diseases.

What are the general orientations of medical and research activities now in the Royan Institute?

Royan, now, focuses on reproductive biomedicine, biotechnology, stem cell and regenerative medicine. In reproductive medicine, we are trying to increase the rate of fertilization and improve the "health" of embryos. In biotechnology, we are producing recombinant or pharmaceutical proteins by using transgenic animals and cell lines. In stem cell research, we are presently focusing on pilot research in order to improve scientific insights, and in parallel we aim at finding reliable connections between our novel scientific achievements and the treatment of various disorders.

Can you tell us more about the impact of the Royan Institute on the advancement of science in Iran? What position do you think it now has in terms of international impact? It is said to be one of the most important and dynamic research institutes in reproductive, stem cell and developmental biology in the Middle East. Do you think this is the case? Do you hope to set an example in this region of the world?

Yes, current scientific achievements at the Royan Institute have put its name as one of the best institutes for reproductive biology and medicine, stem cells and developmental biology, not only in Iran, but also in the Middle East. In particular, these achievements have promoted the Royan Institute as one of the most prestigious institutes studying stem cell biology. The presence of highly experienced scientists within this institute should help us to also assist and support other national or international institutes in the Middle East region involved in the development of these scientific areas.

Regarding your position within the international scientific scene, you clearly show a will to be open to collaborations with scientists from all over the world. What were the strategies promoted by the Royan Institute to help establish contact with scientists all over the world? Would you please explain why this is so important for you?

Obviously, scientific collaborations are not only advantageous for scientists, but they also benefit patients and mankind because they help find new treatments for various human diseases and disorders. Therefore, it is an essential part of Royan's ideology to assist world scientists so that they find better and more adequate treatment approaches for different diseases. Most of the scientists at the Royan Institute graduated in Iranian universities and the rest graduated in other developed countries in various fields of biomedicine. Although we are in a good scientific situation within Iran, we think that it is essential that our scientists collaborate with other scientists from all around the world to contribute to the improvement of knowledge in these areas of science and to the optimization of the corresponding technologies. Collaborations with other scientists also increase the scientific level of our research, widening the fields to new concepts, and give us the opportunity

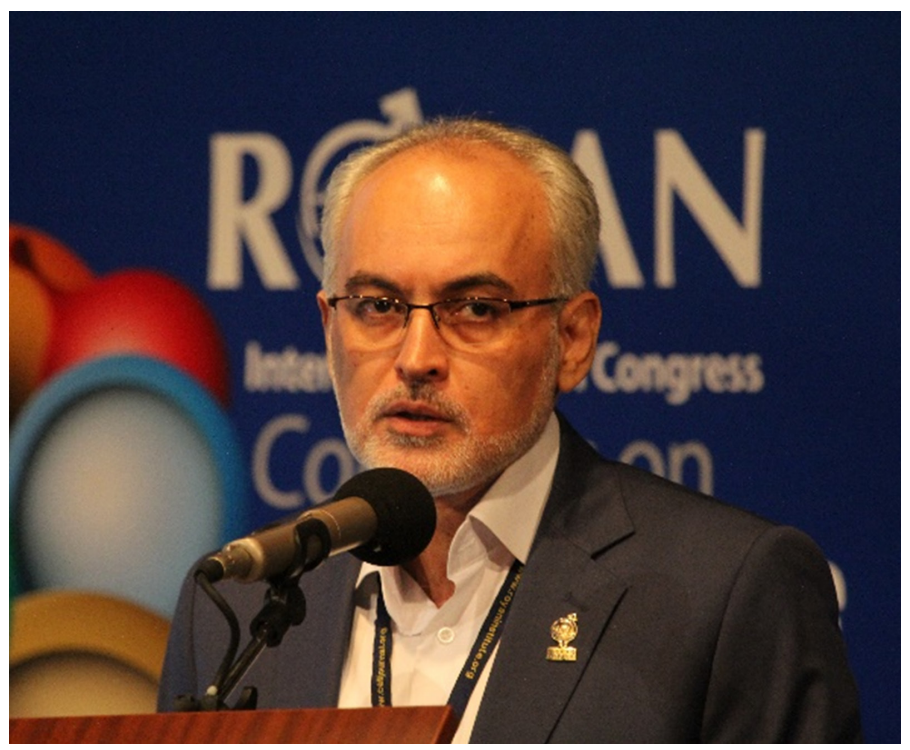

Fig. 4. Prof. Hamid Gourabi, co-founder, current President of the Royan Institute, during the International Royan Conference, (Tehran, Iran, Sept. 2014).

to do part of our research outside the Royan Institute and of Iran, and at the same time, by means of close collaborations with our scientific partners abroad, we can get access to state of the art instruments.

What impact do you think the Royan Institute has had on the relationships between Iranian scientists and their colleagues in other countries? Would you give us one or two examples of fruitful interactions and collaborations?

In addition to the benefits mentioned above, consultations and collaborations with our colleagues from other countries should help us towards a common goal, which is the development of novel approaches to treat many disorders. This is well exemplified by the participation of Royan scientists in international congresses all over the world. The International Royan Congress, held annually in September, is also one of the best opportunities for scientists not only from the Royan Institute, but also from other research centres, to discuss potential collaborations. For example, presently, the stem cell biology and technology department of the Royan Institute is involved in many different international collaborations with different scientific institutions around the world, most of which are well known in the stem cell biology research field.

During my visit, I heard that Prof. Hossein Baharvand, director of Iran's Royan Institute for Stem Cell Biology and Technology, recently won the prestigious UNESCO prize. Would you please let us know more about him and his involvement in research at Royan?

Well, Hossein Baharvand is an Iranian stem cell and developmental biologist who is currently director of the Royan Institute for Stem Cell Biology and Technology. He was awarded his PhD in 2004 in the field of developmental biology from Kharazmi University (Tehran, Iran). He is currently a professor and also the head of the Stem Cell and Developmental Biology Department at the University of Science and Culture in Tehran. Since 2003, he has 
established several human embryonic stem cell lines as well as induced pluripotent stem cells. He is currently working on the conversion between different stem cell types. He has published more than 190 peer-reviewed articles, 9 Persian books and 4 chapters in international books. He is currently a member of the editorial board of five international journals and has won 11 national and international awards. The most recent prize he has been awarded is the UNESCO Equatorial-Guinea International Prize, as a consequence of his effective scientific research in life sciences associated with the aim of improving the quality of human life. He is not only a very good scientist, but also a skilled manager in the scientific area. He has reached this prestigious scientific level while working in a country under economic sanctions. Many people, not only at the Royan Institute and Iran, but also from all over the world, have high respect for him in particular for his ability to find ways for improving treatments and curing diseases. He is therefore a good model for Iranian students to follow, both in dealing with scientific issues and being able to work in difficult conditions.

\section{A portrait of Prof. Hamid Gourabi}

Hamid Gourabi obtained his PhD degree in 1997. Beside the late Prof. Saeid Kazemi, he was one of the cofounders and a member of the Board of Directors of the Royan Institute. He was an academic staff member of the Iran Medical Sciences University for eight years and of the Royan Institute since 2001. In 2004 he was selected as Head of the Genetics Department at the Royan Institute. Since 2006, he has been the President of the Royan Institute. $\mathrm{He}$ is the pioneer of pre-implantation genetic diagnosis
(PGD) in Iran. His main research interests are PGD and stem cell biology and radiobiology. He has co-authored more than a 100 papers in international peer-reviewed scientific journals.

\section{Selected References}

BAHARVAND, H., ASHTIANI, S.K., VALOJERDI, M.R., SHAHVERDI, A., TAEE, A., and SABOUR, D. (2004). Establishment and in vitro differentiation of a new embryonic stem cell line from human blastocyst. Differentiation 72: 224-229. Report of the establishment of Royan Institute's first embryonic stem cell line.

BAHARVAND, H., HAJHEIDARI, M., ASHTIANI, S.K and SALEKDEH, G.H. (2006) Proteomic signature of human embryonic stem cells. Proteomics 6: 3544-3549. First report about hESC proteome in Royan Institute.

KAZEMI-ASHTIANI, S., NASR-ESFAHANI, M.H., MORTAZA-HOSSEINI, S., et al. (2008). ROYANA: Successful Experience in Cloning the Sheep. Cell J. (Yakhteh) 10: 193-200. First lamb cloned in Royan Inst.

AMPS, K., ANDREWS, P.W., ANYFANTIS, G., et al. (2011). Screening ethnically diverse human embryonic stem cells identifies a chromosome 20 minimal amplicon conferring growth advantage. Nat Biotechnol 29: 1132-1144. Report on stem cell initiative, of which Royan is a member.

MIREMADI, T., SALEKDEH, G.H., AGHDAMI, N., et al. (2012). Stem cell research and therapy in the Islamic republic of Iran: pioneering in the Islamic world. Stem Cells Dev 22: 51-7. Progress on Stem cell research in Iran, which was initiated by Royan Institute.

JANGRAVI, Z., ALIKHANI, M., AREFNEZHAD, B., et al. (2013). A fresh look at the male-specific region of the human Y chromosome. J Proteome Res 12: 6-22. First report of Royan in this special issue on "Chromosome centric human proteome project".

AMIRI-YEKTA, A., DALMAN, A., EFTEKHARI-YAZDI, P., et al. (2013). Production of transgenic goats expressing human coagulation factor IX in the mammary glands after nuclear transfer using transfected fetal fibroblast cells. Transgenic Res 22: 131-142. First transgenic goats. 


\section{Further Related Reading, published previously in the Int. J. Dev. Biol.}

1st Royan Institute International Summer School on Developmental Biology and Stem Cells

Bernard A.J. Roelen and Susana M. Chuva de Sousa Lopes

Int. J. Dev. Biol. (2011) 55: 1-4

Neuronal induction and regional identity by co-culture of adherent human embryonic stem cells with chicken notochords and somites Hossein Salehi, Khadijeh Karbalaie, Shahnaz Razavi, Somaieh Tanhaee, Marziyh Nematollahi, Mohsen Sagha, Mohammad-Hossein NasrEsfahani and Hossein Baharvand

Int. J. Dev. Biol. (2011) 55: 321-326

\section{Induced in vitro differentiation of neural-like cells from human exfoliated deciduous teeth-derived stem cells}

Nosrat Nourbakhsh, Mitra Soleimani, Zahra Taghipour, Khadijeh Karbalaie, Seeid-Behrouz Mousavi, Ardeshir Talebi, Fatemeh Nadali, Somayeh Tanhaei, Gholam-Abbas Kiyani, Marziyeh Nematollahi, Farzaneh Rabiei, Mohammad Mardani, Hamid Bahramiyan, Mahmood Torabinejad, Mohammad-Hossein Nasr-Esfahani and Hossein Baharvand

Int. J. Dev. Biol. (2011) 55: 189-195

Feeder- and serum-free establishment and expansion of human induced pluripotent stem cells Mehdi Totonchi, Adeleh Taei, Ali Seifinejad, Mohammadsharif Tabebordbar, Hassan Rassouli, Ali Farrokhi, Hamid Gourabi, Nasser Aghdami, Ghasem Hosseini-Salekdeh and Hossein Baharvand

Int. J. Dev. Biol. (2010) 54: 877-886

Neurogenic and mitotic effects of dehydroepiandrosteroneon neuronal-competent marrow mesenchymal stem cells

Esmaeil H. Shiri, Narges-Zare Mehrjardi, Mahmood Tavallaei, Saeid K. Ashtiani and Hossein Baharvand

Int. J. Dev. Biol. (2009) 53: 579-584

Neural differentiation from human embryonic stem cells in a defined adherent culture condition

Hossein Baharvand, Narges-Zare Mehrjardi, Maryam Hatami, Sahar Kiani, Mahendra Rao and Mahdi-Montazer Haghighi

Int. J. Dev. Biol. (2007) 51: 371-378

Differentiation of human embryonic stem cells into hepatocytes in 2D and 3D culture systems in vitro

Hossein Baharvand, Seyed M. Hashemi, Saeid Kazemi Ashtiani and Ali Farrokhi Int. J. Dev. Biol. (2006) 50: 645-652

5 yr ISI Impact Factor $(2011)=2.959$
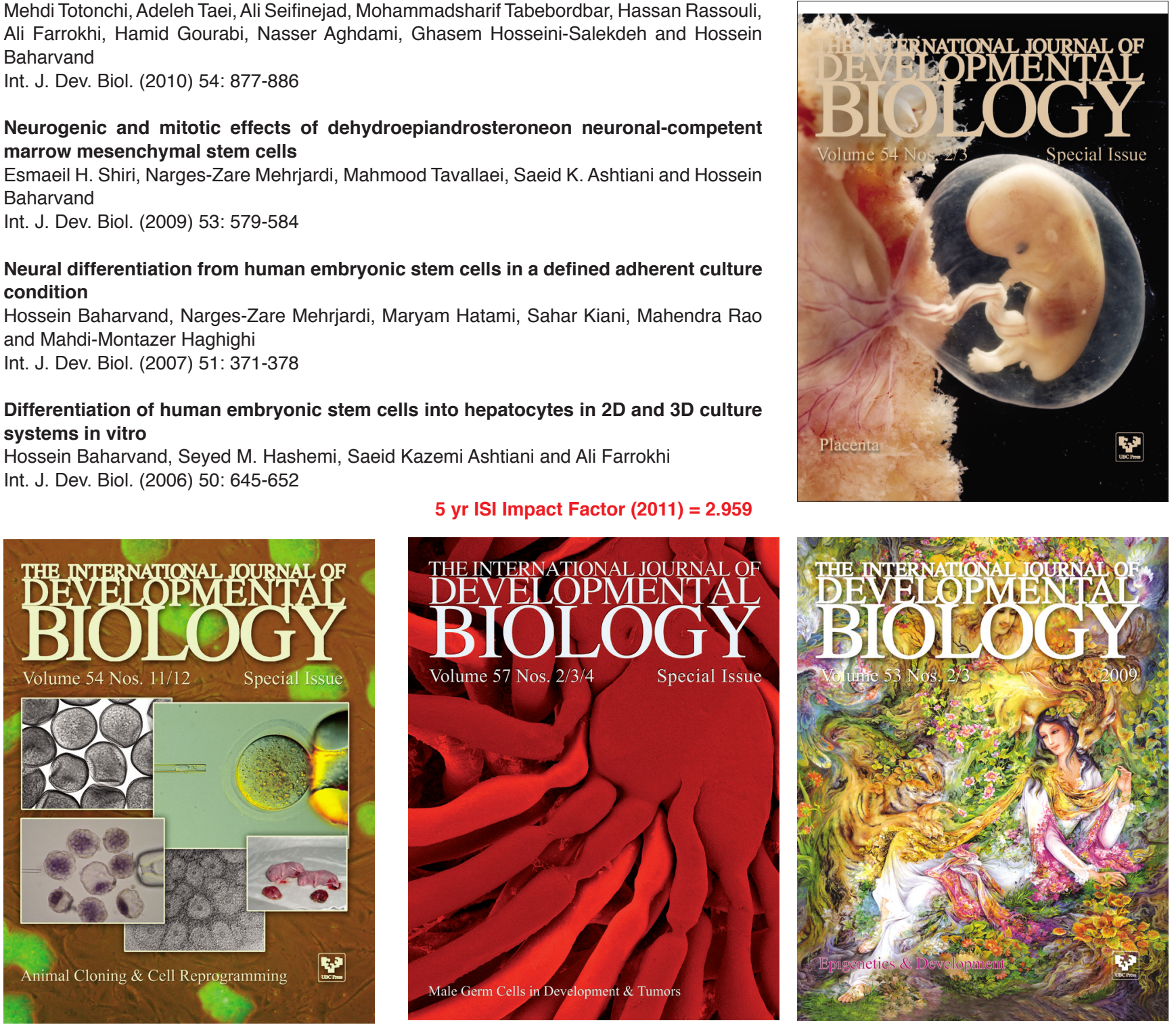